\title{
Consent, Rights, and Reasons for Action
}

\author{
Richard Healey ${ }^{1}$ \\ Published online: 28 October 2018 \\ (C) The Author(s) 2018
}

\begin{abstract}
The normative power of consent plays a central role in enabling individuals to permissibly interact with one another. However, in the philosophical literature, the relationship between consent and permissible action is not always well understood. In this article I outline an account of the normative effect of valid consent, in order to clarify this relationship. I first argue that consent's primary moral significance lies in its effect upon our interpersonal moral relationships. Specifically, I argue that valid consent serves to cancel a directed duty owed to the consenter. Other things being equal, this equips the consentee with a directed permission: they will no longer wrong the consenter by acting in the consented to manner. However, this account does not yet explain how consent impacts upon the all things considered permissibility of an action. On the assumption that all things considered permissibility is a function of an agent's reasons for action, we require an account of consent's effect on those reasons. I consider, and then reject, Michelle Dempsey's recent suggestion that consent affects a consentee's reasons for action by granting them an exclusionary permission. I propose that we should instead understand consent to function as a cancelling permission.
\end{abstract}

Keywords Consent $\cdot$ Rights $\cdot$ Wrongs $\cdot$ Permissibility $\cdot$ Reasons for action · Justification

\section{Introduction}

The language of consent is invoked in a variety of contexts in morality and law. For instance, individuals are sometimes said to consent to the imposition of duties, as when a contractor consents to the duties that she is put under by the terms of a contract. Alternatively, agents may be said to consent to practical authorities, such as the state. In these cases, valid consent will mean that the consenter acquires a

Richard Healey

rjhealey2@gmail.com

1 Department of Philosophy, School of Humanities, University of Glasgow, 67-69 Oakfield Avenue, Glasgow G12 8QQ, UK 
liability to have her normative situation changed through the imposition of duties by the authority in question. ${ }^{1}$

My focus in this article, by contrast, is on what is sometimes called "permissive consent." (I will refer to this notion as "consent" and "permissive consent" interchangeably in what follows.) It is widely recognised that the moral power of consent plays a central role in making a wide variety of actions and activities permissible, such as sexual relations, medical interventions, and the sharing of property. However, in philosophical treatments of consent, the precise nature of the relationship between consent and permissible action is often unclear. It may seem natural to say that the normative effect of consent just is that it makes an impermissible action permissible. Heidi Hurd claims, for example, that valid consent serves to "transform the morality of another's conduct - to make an action right when it would otherwise have been wrong." Similarly, David Enoch suggests that, "Consent ... can render impermissible things permissible (like your touching me, or your using my property)." ${ }^{3}$ Yet examples make clear that these straightforward descriptions are inadequate. For instance:

Surgeons' Consent: Two Surgeons, Steve and Sally, give one another voluntary and informed consent to have sex with each other. They have sex when they are both scheduled to be in the operating theatre saving Zack's life.

Clearly, the fact that Steve and Sally have one another's sexual consent makes an important difference to the moral quality of their actions. In particular, it presumably makes an important difference to their interpersonal moral relationship. However, it is also clear that we cannot simply describe their actions as "right" or "permissible"- after all, they should be saving Zack's life. An adequate account of consent, then, should explain the interpersonal moral difference that Steve's and Sally's consent makes without implying that it is straightforwardly permissible for them to have sex. At the same time, it is clear that valid consent can often ensure that an action is all things considered permissible. If Steve and Sally are at home and off-duty, for example, then other things being equal, their mutual consent will ensure that they are both all things considered permitted to have sex. So an account of consent's normative force should also explain how it impacts upon the all things considered permissibility of an action.

In this article, I develop an account of the normative effect of valid consent that clarifies the nature of the relationship between consent and permissible action. ${ }^{4}$ In Sect. 2, I argue that consent's primary moral significance lies in its effects upon our interpersonal moral relationships. Specifically, I argue that valid consent cancels a

\footnotetext{
${ }^{1}$ For discussion of different uses of the language of consent see, for instance, A.J. Simmons, "Tacit Consent and Political Obligation," Philosophy and Public Affairs 5 (1976): 274-291; Joseph Raz, The Morality of Freedom (Oxford: Oxford University Press, 1986), pp. 80-88.

2 Heidi M. Hurd, "The Moral Magic of Consent," Legal Theory 2 (1996): 121-146, at p. 123.

3 David Enoch, "Hypothetical Consent and the Value(s) of Autonomy," Ethics 128 (2017): 6-36, at p. 8.

4 My focus in this article is on the moral effect of valid consent. While I take it that the correct account of consent's moral significance will be central to thinking about how consent should operate in the law, I cannot draw out any legal implications of the view here.
} 
directed duty that is grounded in a claim-right of the consenter. ${ }^{5}$ Other things being equal, this equips the consentee with what I refer to as a "directed permission": she will no longer wrong the consenter by acting. However, this account does not yet explain how consent impacts upon the all things considered permissibility of an action. I take up the relationship between consent and all things considered permissibility in Sect. 3. On the assumption that all things considered permissibility is a function of an agent's reasons for action, we require an account of consent's effect on those reasons. I first consider, and then reject, Michelle Dempsey's suggestion that consent affects a consentee's reasons for action by granting her an exclusionary permission. ${ }^{6}$ Dempsey's account goes wrong, I suggest, because it fails to take into account the distinctive structure of the reasons grounded in the claim-rights and directed duties over which consent gives us normative power. I then propose that we can helpfully conceive of these right-based reasons as protected reasons, and argue that consent affects a consentee's reasons for action by cancelling this protective structure. Section 4 concludes.

\section{Consent and Directed Permissions}

Consent is paradigmatically required from an individual when we wish to act in some way that would normally violate a claim-right of hers and thereby wrong her. For example, if you wanted to practice your hairdressing skills on me, you would need to acquire my consent in order to do so without violating a claim-right of mine to control who touches my body. Likewise, if you hope to use a painting of mine for firewood, I will need to give you my consent if you are to avoid violating my property right by doing so.

As these examples illustrate, what is primarily at stake in these contexts is the moral relationship between the consenter and consentee. Specifically, what is of central concern is whether the consentee will wrong the consenter by violating a claimright of hers, thereby failing to abide by a directed duty owed to the consenter. That the consenter has this claim-right, and the consentee owes this duty to the consenter, establishes an important form of normative relationship between consenter and consentee. The consenter can legitimately expect that the consentee will refrain from acting contrary to her right unless the consentee first acquires her consent. ${ }^{7}$ Where the consentee fails in this regard, the consenter will have a privileged standing to make a complaint against the consentee, and a special basis for reactive attitudes such as blame and resentment. ${ }^{8}$

\footnotetext{
5 This statement will need to be slightly refined below.

6 Michelle Dempsey, "Victimless Conduct and the Volenti Maxim: How Consent Works," Criminal Law and Philosophy 7 (2013): 11-27.

7 This is something of a simplification, since there may be other ways of the consenter's ceasing to have a claim-right against the consentee. I leave this complication aside in what follows.

8 See, e.g., R. Jay Wallace, "The Deontic Structure of Morality," in Thinking about Reasons: Essays in Honour of Jonathan Dancy, edited by David Bakhurt, Brad Hooker, and Margaret Olivia Little (Oxford: Oxford University Press, 2013): 137-167.
} 
These considerations support the following view of permissive consent's normative effect. ${ }^{9}$

Permissive Consent: When $\mathrm{X}$ gives valid consent to $\mathrm{Y}$ to $\phi$, she thereby cancels a directed duty that $\mathrm{Y}$ owes to $\mathrm{X}$ (or X's ward) not to $\phi$ that is grounded in a claim-right of $\mathrm{X}$ (or X's ward). ${ }^{10}$

In order to support and elucidate this view, consider again the previous examples. If I give you consent to cut my hair, then, plausibly, I cancel the normal duty you owe me to refrain from touching my hair, a duty grounded in my more general claimright to control over my own body. ${ }^{11}$ Likewise, if I consent to your destroying a painting that I own, I release you from the normal duty you owe me not to do so. If this is correct, then, other things being equal, my consent will give you a directed permission:

Directed Permission: $\mathrm{Y}$ has a directed permission to $\phi$ with regard to $\mathrm{X}$ when he will not wrong $\mathrm{X}$ by $\phi$-ing. ${ }^{12}$

A directed permission is, we might say, the flip side of a directed duty: if $\mathrm{Y}$ owes $\mathrm{X}$ a directed duty not to $\phi$, he will wrong her by $\phi$-ing; if $\mathrm{Y}$ has a directed permission with regard to $X$ to $\phi$, then he will not wrong her by $\phi$-ing. ${ }^{13}$

Being clear that X's consent (usually) gives $\mathrm{Y}$ a directed permission to $\phi$ makes explicit that consent is directly connected to, and primarily concerned with, the

\footnotetext{
${ }^{9} \mathrm{I}$ am assuming throughout that consent is valid, meaning that it is sufficiently voluntary and informed to have its normative effect. I leave aside the issue of what exactly is required for $\mathrm{X}$ to give consent to $\mathrm{Y}$.

${ }^{10}$ Something like this view is suggested by a number of authors. See, in particular, Tom Dougherty, "Yes Means Yes: Consent as Communication," Philosophy and Public Affairs 43 (2015): 224-253, at pp. 232-233; Joel Feinberg, Harm to Self (Oxford: Oxford University Press, 1986), pp. 176-180; Victor Tadros, Wrongs and Crimes (Oxford: Oxford University Press, 2016): Ch. 11; R. Jay Wallace, "Reasons, Relations, and Commands: Reflections on Darwall," Ethics 118 (2007): 24-36, at pp. 29-30. The disjunctive formulation (... of X or X's ward ...) is to allow for cases in which an agent has a power of consent over duties owed primarily to another, such as, for example, a parent's having power of consent over duties owed to her child. Whether and how such powers are justified are difficult questions. I will focus here on standard two-party cases in which the consenter and bearer of the claim-right are identical.

${ }^{11}$ I assume here, following Raz, that claim-rights are the grounds of duties in others. See Raz, The Morality of Freedom, Ch. 7. Nothing hangs on this assumption, and my argument is consistent with alternative views of the relationship between rights and duties.

${ }^{12}$ Cf. H.L.A. Hart, “Are There Any Natural Rights?," The Philosophical Review 64 (1955): 175-191, at p. 184.

13 On directed duties in general see, Margaret Gilbert, "Scanlon on Promissory Obligation: The Problem of Promisees' Rights," The Journal of Philosophy 101 (2004): 83-109; Michael Thompson, "What is it to Wrong Someone? A Puzzle about Justice," in Reason and Value: Themes from the Moral Philosophy of Joseph Raz, edited by R. Jay Wallace, Philip Pettit, Samuel Scheffler, and Michael Smith (Oxford: Clarendon Press, 2004): 333-384. The notion of a directed permission is closely related to the notion of a Hohfeldian privilege (or liberty) right. Indeed, the notion of a privilege is sometimes invoked in discussions of consent's normative effect. See, e.g., Feinberg, Harm to Self; and Judith Jarvis Thomson, The Realm of Rights (Cambridge: Harvard University Press, 1990), Ch. 14. I avoid using the notion of a privilege, however, because as the notion is often employed, it is ambiguous. Specifically, saying only that $\mathrm{Y}$ has a privilege to $\phi$ does not make it clear whether (i) $\mathrm{Y}$ owes no duty to $X$ not to $\phi$, or (ii) $Y$ owes no duty to anyone (or perhaps simply no duty at all-whether directed or non-directed) not to $\phi$. The notion of a directed permission helps to make clear that consent's primary effect is on (i) rather than (ii).
} 
interpersonal moral relationship between $\mathrm{X}$ and Y. Specifically, it is connected with whether Y wrongs $\mathrm{X}$ by violating a directed duty he owes to her. It is not directly connected to the more general notions of "right and wrong action" or "permissible and impermissible action." 14 The import of this is perhaps obvious, but it is important. The fact that X's consent ensures that $\mathrm{Y}$ has a directed permission with regard to her to $\phi$ does not entail either that (i) $\mathrm{X}$ has a directed permission with regard to any other agent to $\phi$, or (ii) that X's $\phi$-ing is all things considered permissible. To make these claims clear, consider two examples.

Salad: $\mathrm{X}$ gives $\mathrm{Y}$ consent to eat her salad. However, $\mathrm{Y}$ has promised $\mathrm{Z}$ that he will not eat X's salad.

Beautiful Painting: X owns a painting, which is an undisputed work of beauty and artistic genius. $\mathrm{X}$ gives $\mathrm{Y}$ consent to destroy the painting.

In Salad, while X's consent ensures that Y has a directed permission to eat the salad with regard to $\mathrm{X}$, Y's promise to $\mathrm{Z}$ means that he owes $\mathrm{Z}$ a directed duty not to eat the salad, and thus entails that $Y$ does not have a directed permission to eat the salad with regard to $Z$. Thus, while $X$ 's consent makes an important difference to $X$ and Y's moral relationship, insofar as it prevents $\mathrm{Y}$ from wronging $\mathrm{X}$ if he eats her salad, this has no bearing on the moral relationship that obtains between $\mathrm{Y}$ and $\mathrm{Z}$ in virtue of Y's promise.

In Beautiful Painting, by contrast, Y may be under a general duty (as opposed to a directed duty owed to any particular agent) not to destroy great works of art. In this case, $\mathrm{Y}$ has a directed permission with regard to $\mathrm{X}$ to destroy the painting (and, we can further assume, a directed permission with regard to all individual agents, since no individual has a claim-right against Y's destroying the painting). However, Y's non-directed duty to respect great artwork may suffice to ensure that Y's destroying the painting is not all things considered permissible. ${ }^{15}$

A further less obvious consequence of Permissive Consent is that X's consent that $\mathrm{Y} \phi$ does not straightforwardly entail that $\mathrm{Y}$ has a directed permission with regard to $X$ to $\phi$. That is to say, it is possible that $\mathrm{Y}$ will wrong $\mathrm{X}$ by $\phi$-ing even when $\mathrm{X}$ has given $\mathrm{Y}$ valid consent to $\phi$. The reason for this is that $\mathrm{Y}$ may owe $\mathrm{X}$ multiple and independent duties not to $\phi$ (duties that are individuated by their basis, e.g., their basis in different morally significant features of a person). Imagine, for example, that a Patient is sick and that the Surgeon is considering whether she should perform Procedure 1 or Procedure 2. Further imagine that Patient gives Surgeon consent to perform either Procedure 1 or Procedure 2. Assumedly, Patient's consent releases

\footnotetext{
${ }^{14}$ Cf. Enoch, "Hypothetical Consent"; Nir Eyal, "Informed Consent," in The Stanford Encyclopaedia of Philosophy (Fall 2012 Edition), ed. Edward N. Zalta, URL = http://plato.stanford.edu/archives/fall2012/ entries/informed-consent/; Hurd, "The Moral Magic of Consent"; John Kleinig, "Consent," in The International Encyclopaedia of Ethics, edited by Hugh LaFollette (Oxford: Blackwell, 2013): 1-6.

15 I discuss one view of what it means for an action to be all things considered permissible in more detail in Sect. 3.
} 
Surgeon from her normal duty not to engage in the painful and invasive surgery of the kind involved in both Procedure 1 and Procedure 2. However, Surgeon may have a further duty of care to Patient to perform only the procedure she reasonably believes will be best for Patient. Thus, if Surgeon decides Procedure 1 is much more likely to be better for Patient than Procedure 2, she will violate her duty of care and thereby wrong Patient if she opts to perform Procedure 2, even though she has Patient's consent to perform Procedure 1 or Procedure 2.

Having outlined the view we are now able to make sense of the example with which we began. Recall:

Surgeons' Consent: Two Surgeons, Steve and Sally, give one another voluntary and informed consent to have sex with each other. They have sex when they are both scheduled to be in the operating theatre saving Zack's life.

By giving consent, Steve and Sally both cancel the normal directed duty they owe one another not to have sex with the other. This means that neither Steve nor Sally wrongs the other when they do have sex (on the plausible assumption that they owe one another no independent directed duty not to do so), such that they both have a directed permission to have sex with the other. Thus, Steve's and Sally's consent means that neither of them has standing to complain against the other about the sexual contact in which they engage. However, nothing follows from this fact about other reasons or duties that they each have, and so nothing follows directly about either (i) whether they owe further directed duties to other individuals (e.g., Zack) that count against their having sex, or (ii) the all things considered permissibility of their action. Since, we can assume, Steve and Sally each owe Zack a duty of care, they will seriously wrong him by failing to operate. Thus, both Steve and Sally lack a directed permission with regard to Zack to have sex with one another. Furthermore, it is plausible given the weight of their duty of care that Steve and Sally having sex is all things considered impermissible. Nevertheless, Steve's and Sally's sexual consent still plays a very important role with regard to their interpersonal moral relationship, since it ensures that neither of them commits the serious wrong of having non-consensual sex against the other.

\section{All Things Considered Permissibility and Reasons for Action}

Permissive Consent accounts for the important role that consent plays in our interpersonal moral relationships. It says that valid consent cancels a directed duty owed to the consenter, and thereby (usually) forestalls the possibility of the consentee wronging the consenter. If this view is correct, it follows that consent's effect upon the all things considered permissibility of an action is indirect. It is a consequence of consent's cancellation of a directed duty. Plausibly (and so I will assume), the all thing considered permissibility of X's $\phi$-ing is a function of the reasons that $\mathrm{X}$ has for and against $\phi$-ing. Thus, in order to account for consent's effect upon all things considered permissibility, we require an account of how consent affects a consentee's reasons for action. 


\subsection{Consent as an Exclusionary Permission}

Dempsey has argued that X's consent affects Y's reasons for action by providing $\mathrm{Y}$ with an exclusionary permission. ${ }^{16}$ An "exclusionary permission" is, roughly, a permission to disregard some of the reasons that count for or against the performance of an action. For example, if $\mathrm{Y}$ has a reason not to punch $\mathrm{X}$ because doing so will cause $\mathrm{X}$ pain, $\mathrm{X}$ 's granting $\mathrm{Y}$ an exclusionary permission with regard to this reason allows $\mathrm{Y}$ to disregard this pain-based reason from the reasons that bear on the justification of punching X. According to Dempsey, this explains why X's consent ensures that $\mathrm{Y}$ can permissibly punch $\mathrm{X}$; in order to justify punching $\mathrm{X}, \mathrm{Y}$ is no longer required to take into consideration the very reason that usually explains why punching $\mathrm{X}$ will wrong her.

Dempsey's view is suggestive, but ultimately incorrect. In order to see this, let me begin by sketching Dempsey's position in a little more detail. Dempsey starts by outlining the two conditions under which she believes Y's $\phi$-ing calls for X's consent:

(i) Y's $\phi$-ing calls for justification (i.e., there are non-trivial reasons not to $\phi$ ). ${ }^{17}$

(ii) At least one reason in virtue of which Y's $\phi$-ing calls for justification is grounded in X's well-being. ${ }^{18}$

In setting out her view, Dempsey focuses on the example in which $\mathrm{Y}$ punches $\mathrm{X}$, so let's continue with that example. According to Dempsey, Y requires X's consent in order to permissibly punch $\mathrm{X}$ because $\mathrm{Y}$ 's punching $\mathrm{X}$ calls for justification, and because at least one of the reasons that this is so is grounded in X's well-being, e.g., the fact that the punch will cause $\mathrm{X}$ pain. ${ }^{19}$ For ease, we can label the reasons grounded in X's well-being as reasons R. Usually R mean that $\mathrm{Y}$ will wrong $\mathrm{X}$ by punching her. The question, then, is how $X$ 's consent affects the reason-giving force of $\mathrm{R}$ so that $\mathrm{Y}$ 's punching $\mathrm{X}$ will not wrong her.

Dempsey's claim, as I have said, is that consent restricts the reason-giving force of $\mathrm{R}$ by providing $\mathrm{Y}$ with an exclusionary permission with regard to $\mathrm{R}$ : a permission to exclude the reason-giving force of $\mathrm{R}$ from the reasons that bear on punching $\mathrm{X}$. That is to say, $\mathrm{Y}$ is permitted (although not required) not to weigh the fact that punching $\mathrm{X}$ will cause $\mathrm{X}$ pain in his practical deliberations. ${ }^{20}$ If $\mathrm{Y}$ choses to take up this exclusionary permission, it will have an important effect on the balance of

\footnotetext{
${ }^{16}$ Dempsey, "Victimless Conduct and the Volenti Maxim: How Consent Works.".

${ }^{17}$ Dempsey, "Victimless Conduct," p. 16 and fn. 10.

18 Dempsey, "Victimless Conduct," p. 16.

${ }^{19}$ Compare a case in which one reason not to punch $\mathrm{X}$ is that it will get blood on a third-party (Z's) shirt. Whilst we can assume that this a reason for $\mathrm{Y}$ not to punch $\mathrm{X}$, this reason alone does not call for Y to obtain X's consent, on Dempsey's view, because the reason is not grounded in X's well-being. See ibid.

${ }^{20}$ Note that, while $\mathrm{Y}$ is not required to take up the exclusionary permission, on Dempsey's view, $\mathrm{Y}$ must do so if he is to avoid wronging $\mathrm{X}$ by $\phi$-ing.
} 
reasons that $\mathrm{Y}$ has for and against punching $\mathrm{X} .{ }^{21}$ Specifically, if the reasons in $\mathrm{R}$ include all the reasons that $\mathrm{Y}$ would normally have not to punch $\mathrm{X}$ that are grounded in X's well-being, then Y's permission to exclude these reasons will, if Y takes up the exclusionary permission, give $\mathrm{Y}$ a directed permission to punch $\mathrm{X}$.

However, Dempsey's view fails to explain paradigmatic cases in which consent or non-consent determines whether an act constitutes a wronging. That is because, I want to suggest, she mistakenly claims that the reasons that call for consent, and so the reasons upon which consent has an effect, are ordinary first-order reasons for action grounded in X's well-being, as opposed to reasons grounded in X's claim-rights.

To draw this out, recall first that, according to Dempsey, Y requires X's consent to $\phi$ in order not to wrong $X$ by $\phi$-ing just when (i) $\phi$-ing calls for justification for (ii) at least one reason grounded in X's well-being. On the two most straightforward readings of these conditions, they are both over- and under-inclusive. On a first reading, these conditions would mean that $Y$ requires X's consent in any case in which Y's action would set back an interest of X's. This would then have the implication that any action of Y's that sets back X's interest wrongs $\mathrm{X}$ unless $\mathrm{X}$ has given $\mathrm{Y}$ consent. Yet this is clearly false. I do not require your consent not to wrong you by buying the last available cinema seats, even though I may set back your interests by doing so (perhaps you really need to see the film in order to finish a school project). Similarly, my partner does not require my consent in order not to wrong me by ending our relationship, even though she may seriously set back my interests in so doing. The point, simply put, is that not all non-consensual harms constitute wrongings.

Perhaps, however, these cases do not meet condition (i) according to which the act in question requires justification. When does an act require justification? Dempsey does little to spell out condition (i) other than to say in a footnote that justification is called for when an agent's " $\phi$-ing is not merely innocuous conduct," such that the agent "has non-trivial reasons not to $\phi . " 22$ To my mind, this condition supports the reading just rejected. In any case, let us assume that we can identify a sub-set of morally significant interests and that condition (i) is met only when an agent's morally significant interests will be set back by an action. Even then, it is very likely that the view will be over-inclusive. ${ }^{23}$ Imagine, for example, that $\mathrm{Y}$ will cast a ballot in an election, and, given the small size of his constituency, that his vote is likely to

\footnotetext{
21 An interesting feature of Dempsey's view is that in order for consent to have its normative effect there must be uptake from the consentee. Specifically, the consentee must both recognise that she has been given consent and exclude the reasons she has been permitted to exclude from her rational horizons. See the discussion at pp. 22-26. On my own view, it is a further question whether valid consent requires some form of uptake. However, even if it does (as I am inclined to think), this uptake need not take the form of actively excluding certain reasons, as is the case on Dempsey's view.

22 Dempsey, "Victimless Conduct," p. 16 and fn. 10.

23 I say it is only likely to be over-inclusive because without some further specification of the conditions under which an act calls for justification we cannot be certain about which examples will fall under the condition. I offer the following example on the assumption that most will believe that the interests at stake are sufficiently weighty to be "morally significant" in the sense suggested in the text.
} 
make a difference to who is elected. ${ }^{24} \mathrm{Y}$, who is already well off, intends to vote for Party $_{1}$ because Party $_{1}$ will reduce taxes on the rich, in part because Y believes such measures are necessary to foster entrepreneurship. However, Party ${ }_{1}$ intend to pay for this tax cut by reducing funding to important public services, services relied on by the less well off, including X. Here, it is plausible to maintain that Y's voting for Party $_{1}$ calls for justification (in Dempsey's terminology, there are non-trivial reasons not to vote for Party ${ }_{1}$ ), and this is partly for reasons grounded in X's well-being. Nonetheless, it does not follow that $\mathrm{Y}$ owes $\mathrm{X}$ a duty not to vote for Party ${ }_{1}$ unless she first acquires X's consent. Reasonable citizens can disagree about the best way of structuring the tax system and financing public services, and $\mathrm{Y}$ has a right to vote for whomever he wishes. Even though we can surely evaluate Y's behaviour and criticise his choice partly for reasons grounded in X's well-being, Y's voting for Party $_{1}$ does not call for X's consent. ${ }^{25}$

Turn now to the under-inclusivity of Dempsey's view. If consent is only called for under the conditions described, Dempsey's view cannot accommodate cases of harmless wronging: cases in which $\mathrm{Y}$ wrongs $\mathrm{X}$ but without setting back any interest of X's. ${ }^{26}$ Imagine, for example, that $\mathrm{Y}$ takes a mouth swab from $\mathrm{X}$ whilst $\mathrm{X}$ is in a deep sleep without causing any harm to $X$, and without $X$ ever finding out. ${ }^{27}$ Alternatively, imagine that Y borrows X's car whilst X is away on holiday, without doing any damage to the car, refilling the tank before returning the vehicle, and so on. Most people will hold that $\mathrm{Y}$ has wronged $\mathrm{X}$ by acting in these ways without first acquiring X's consent, despite the fact that no interest of X's has been set back by Y's acting. But Dempsey's view cannot explain why X's consent would be called for in such cases, and so cannot explain why it is that $\mathrm{Y}$ would wrong $\mathrm{X}$ by acting without consent. That is because, ex hypothesi, there are no reasons for $\mathrm{Y}$ not to take the swab or borrow the car that are grounded in X's well-being. ${ }^{28}$

\footnotetext{
${ }^{24}$ Thanks to Angie Pepper for this example.

${ }^{25}$ Cf. Jeremy Waldron, "A Right to Do Wrong" Ethics 92 (1981): 21-39.

${ }^{26}$ See, generally, Arthur Ripstein, "Beyond the Harm Principle," Philosophy and Public Affairs 34 (2006): 215-245; David Owens, Shaping the Normative Landscape (Oxford: Oxford University Press, 2012).

${ }^{27}$ This example is from David Archard, "Informed Consent: Autonomy and Self-Ownership," Journal of Applied Philosophy 25 (2008): 19-34, at p. 19.

28 An anonymous reviewer has suggested that I may wrongly be assuming that by "well-being" Dempsey means only "harms and benefits," while in fact the category of well-being is meant to be broader. If so, Dempsey may be able to avoid the charge of under-inclusivity, since she may say that we may have interests in certain actions not being performed (e.g., others using our property) even if those actions would not harm us. I want to cede that this may be what Dempsey had in mind. However, I do not think this interpretation is well supported by the text, where Dempsey's central example of a set back to well-being is the pain and suffering caused by one agent's punching another, which is a paradigm case of harm. Moreover, even if this were Dempsey's intended usage, without a more detailed story about when and why we can have interests in others not performing certain actions independent of the fact that it would harm us or because we have a right against their doing so, it is somewhat ad hoc to simply appeal to our possession of an interest in these cases of under-inclusivity.
} 


\subsection{Claim-Rights and Directed Duties as Protected Reasons}

What these examples highlight, I would suggest, is that Dempsey misconceives of the reasons that call for, and are affected by, consent. Simply put, Dempsey errs in assuming that the power of consent is a power over the reasons for or against an action that are directly grounded in an agent's interests, rather than a power over claim-rights and directed duties. This mistake is important, however, because rights and duties play central roles in moral and legal thought because of the distinctive structure of the reasons they give to agents.

On most views, rather than giving agents ordinary reasons in favour of or against a course of action, rights and duties give agents "particularly powerful or weighty reasons," which "override reasons of other sorts." 29 Rights and duties are held to pre-empt or exclude or silence other reasons for action. For example, my normal autonomy rights do not just give doctors a reason not to remove my kidney, but rather give them a reason of a special sort, a reason that cannot simply be weighed against other considerations, such as the fact that my kidney would do more good if given to a patient in need of a kidney transplant. Whilst there is some disagreement about how best to understand this idea, here I will simply outline one popular view, according to which claim-rights and the directed duties they ground give agents "protected reasons." ${ }^{30}$ While I will not defend this view, I believe that its central features accurately capture the idea that claim-rights and directed duties have a special normative force not shared with ordinary reasons for action.

A protected reason to $\phi$ is both a first-order reason to $\phi$, and a second-order reason not to act on some considerations otherwise relevant to the question of whether to $\phi .{ }^{31}$ Some examples will help to clarify this idea. If the drill sergeant orders the troops to fall in she gives the troops a protected reason to fall in: a first-order reason to fall in, and a second-order reason to exclude some of the considerations that would normally bear on whether to fall in, for example, the troops desire to play cards in the mess hall instead. The exclusionary component of the protected reason protects the first-order reason to fall in by depriving other reasons, such as the desirability of playing cards, of their normal justificatory force.

Similarly, consider a situation in which I am sick, and my surgeon believes that the best course of action would be to perform a minor surgical procedure. Since I have a claim-right to control my own body, this places the surgeon under a directed duty not to operate. This claim-right, and the surgeon's concomitant duty, grounds

\footnotetext{
${ }^{29}$ Leif Wenar, "Rights," in The Stanford Encyclopedia of Philosophy (Fall 2015 edition), ed. Edward N. Zalta, $U R L=$ https://plato.stanford.edu/archives/fall2015/entries/rights/.

${ }^{30}$ While not always described in the language of exclusionary and protected reasons that I employ, this idea is widely accepted. See, e.g., See, e.g., Frances Kamm, Intricate Ethics: Rights, Responsibilities, and Permissible Harm (Oxford: Oxford University Press, 2007), p. 237; Jeremy Waldron, "Introduction," in his edited collection Theories of Rights (Oxford: Oxford University Press, 1984): 1-20, at p. 14; Raz, The Morality of Freedom, Ch. 7; T.M. Scanlon, What We Owe To Each Other (Cambridge: Harvard University Press, 1998); and Leif Wenar, "Rights".

${ }^{31}$ Joseph Raz, Practical Reason and Norms, Second Edition (Oxford: Oxford University Press, 1999), p. 192.
} 
a protected reason: the surgeon has a (first-order) reason not to operate upon me, coupled with a (second-order) reason to exclude some otherwise relevant considerations, like the fact that the surgery would (or would not) be good for my physical health, and the fact that I am a perfect test case for a new experimental form of surgery. As with the drill sergeant's order, my claim-right deprives these considerations of whatever justificatory force they would otherwise have. Thus, my right should be seen (barring exceptional circumstances) as settling the matter: if I am conscious and competent, there is little room for the surgeon to deliberate about whether to perform the surgery unless she has my informed consent.

Now, according to Permissive Consent, when $\mathrm{X}$ gives $\mathrm{Y}$ consent to $\phi, \mathrm{X}$ cancels a directed duty that $\mathrm{Y}$ has not to $\phi$ that is grounded in a claim-right of $\mathrm{X}$ or $\mathrm{X}$ 's ward. Thus, on the assumption that Y's directed duty not to $\phi$ is a protected reason, we can say that X's consent cancels this protected reason. Before we can understand how the cancellation of a protected reason will affect a consentee's reasons for action, however, we first need to be more precise about two ways in which protected reasons bear on the deliberative discretion of an agent.

The two ways in which protected reasons bear on an individual's deliberative discretion correspond with the two components of a protected reason: the exclusionary reason, and the first-order reason in favour of $\phi$-ing. First, and more straightforwardly, the exclusionary reason will exclude some competing reasons from the pool of available reasons for action. For example, my claim-right against the surgeon excludes the fact that my kidney could be used to save another's life from constituting a reason in favour of removing my kidney.

Second, the first-order reason to act given by the protected reason will also preempt some other reasons for action. A reason is a pre-emptive reason if it replaces some of the reasons that would otherwise apply in the circumstances. ${ }^{32}$ In this context, the first-order reason that the surgeon has not to operate, that is given to her by my right, also replaces the underlying considerations that justify my right. This must be the case if we are to avoid double counting these reasons. ${ }^{33}$ To understand this pre-emptive feature of protected reasons, consider my autonomy right. This right, and so the reasons given to the surgeon by this right, are, I assume, justified by certain facts about me. It may be, for instance, that I have significant interests in living an autonomous life. Alternatively, it may simply be that, because I am a rational agent, it is fitting that I have control over my own life. In either case, these facts would normally ground reasons that count in favour of letting me make my own decisions about whether to undergo surgery. When these facts are sufficient to ground a right, however, my right pre-empts other agents' (including the surgeon's) direct consideration of these reasons. My right serves, in H.L.A. Hart's words, "to preclude or cut off any independent deliberation by [the surgeon] of the merits pro and con of doing the act." 34 Thus, when deliberating about whether to remove my

\footnotetext{
32 Raz, The Morality of Freedom, p. 186.

33 See ibid., p. 58.

34 H.L.A. Hart, "Commands and Authoritative Reasons" in his Essays on Bentham: Studies in Jurisprudence and Political Theory (Oxford: Oxford University Press, 1982): 243-268, at p. 253. This quote makes too strong a claim, because not all reasons are pre-empted or excluded by a protected reason. For
} 
kidney, it is not open for the surgeon to directly consider my interests in living autonomously, and weigh these against various other considerations. Rather, the surgeon should simply recognise that my right gives her a reason (of a certain weight) not to remove my kidney, as well as an exclusionary reason not to consider certain other reasons in favour of operating.

On the protected-reason model of claim-rights (and directed duties) that I have advanced, X's claim-right that Y not $\phi$ affects Y's reasons for action in three ways. First, X's claim-right gives $Y$ a first-order reason, of a certain weight, not to $\phi .{ }^{35}$ Second, this first-order reason not to $\phi$ pre-empts direct consideration of the reasons in favour of not $\phi$-ing that underlie the justification of the right. Finally, the secondorder exclusionary reason gives $\mathrm{Y}$ a reason to exclude certain considerations that count in favour of $\phi$-ing.

\subsection{Consent as a Cancelling Permission}

We are now in a position to understand how X's consent will affect Y's reasons for action. As I have said, when $\mathrm{X}$ gives $\mathrm{Y}$ consent to $\phi, \mathrm{X}$ cancels a directed duty that $Y$ has not to $\phi$ that is grounded in a claim-right of X or X's ward. More specifically, we can now say that $X$ 's consent functions as a cancelling permission: ${ }^{36}$

Cancelling Permission: When $\mathrm{X}$ grants $\mathrm{Y}$ a cancelling permission to $\phi, \mathrm{X}$ cancels a protected reason $\mathrm{Y}$ has not to $\phi$, and thereby alters the reasons that bear on the justification of Y's $\phi$-ing. Specifically, Y is now able to consider: (i) reasons that count in favour of $\phi$-ing that were previously excluded, and (ii) reasons that count against $\phi$-ing that were previously pre-empted.

We saw above that, by cancelling Y's duty, X's valid consent will (usually) equip Y with a directed permission, preventing $\mathrm{Y}$ from wronging $\mathrm{X}$ by $\phi$-ing. If this cancellation of Y's duty affects Y's reasons for action in the manner described in Cancelling Permission, how will this affect the all things considered permissibility of Y's action?

Footnote 34 (continued)

example, if I promise to pick you up from the airport tomorrow, a minor inconvenience that crops up is now excluded as a reason that can justify my not picking you up, but the fact that my mother is taken seriously ill may not be so excluded.

35 The weight of the first-order reason is, I assume, determined by the weight or significance of the underlying considerations that justify the right. A full consideration of this issue would take us too far afield.

${ }^{36}$ Raz coins the notion of a cancelling permission in The Authority of Law: Essays on Law and Morality (Oxford: Oxford University Press, 1979), p. 18. While closely related, my usage of the label is slightly different from Raz's own. 
For the sake of argument, I will assume (following Dempsey, and John Gardner ${ }^{37}$ ) that an agent's action is justified, and so all things considered permissible, when an agent acts for an undefeated reason. ${ }^{38}$ For $Y$ to have an undefeated reason to $\phi$, he must have a reason that is neither outweighed by any reason that $\mathrm{Y}$ has not to $\phi$, nor excluded by any reason that $\mathrm{Y}$ has. Now, if consent functions as a cancelling permission, $X$ 's consent will affect the all things considered permissibility of Y's $\phi$-ing by altering the reasons that bear on the justification of Y's $\phi$-ing, by enabling $\mathrm{Y}$ to directly consider reasons that were previously pre-empted or excluded by the duty $\mathrm{Y}$ owed to $\mathrm{X}$.

In order to elucidate this idea, consider a simple case. $\mathrm{X}$ has a right against $\mathrm{Y}$ that $\mathrm{Y}$ refrains from punching her in the face. This right usually limits Y's deliberative discretion as to whether to punch $\mathrm{X}$ by (i) excluding some reasons that $\mathrm{Y}$ may have to punch X (e.g., Y's need to practice his martial arts skills), and (ii) pre-empting some of the reasons that count against punching $\mathrm{X}$ (e.g., X's interest in not experiencing pain). If $\mathrm{X}$ gives $\mathrm{Y}$ consent to punch her, and $\mathrm{X}$ 's consent functions as a cancelling permission, this will enable $\mathrm{Y}$ to (i) rely on the previously excluded reasons for punching $\mathrm{X}$, and (ii) enable $\mathrm{Y}$ to directly consider the reasons against punching $\mathrm{X}$. Importantly, as Dempsey and other authors have noted, X's consent that $\mathrm{Y}$ punch her does not provide $\mathrm{Y}$ with any positive reason in favour of punching $\mathrm{X}$. For example, the mere fact that I consent to your touching my knee does not give you any reason to do so. ${ }^{39}$ And, on the account we are assuming here, for Y's punching $\mathrm{X}$ to be all things considered permissible, $\mathrm{Y}$ requires an (undefeated) positive reason to punch X. But X's consent will make a difference to whether Y's punching her is all things considered permissible by altering the range of reasons that are available to $\mathrm{Y}$ in the justification of his action. To keep things simple, imagine that by punching $\mathrm{X}$, $\mathrm{Y}$ can prevent a significant harm from befalling $\mathrm{Z}$. This gives $\mathrm{Y}$ a reason in favour of punching X. Furthermore, thanks to X's consent, Y can consider the reasons against punching $\mathrm{X}$ that are given to him by $\mathrm{X}$ 's interest in avoiding pain. (He no longer has to simply refrain because of X's right.) And assuming that the reasons in favour of punching $\mathrm{X}$ that are given to $\mathrm{Y}$ by the harm that will befall $\mathrm{Z}$ if he does not are much more significant than the reasons against punching $\mathrm{X}, \mathrm{Y}$ is all things considered permitted to punch X.

In general terms, then, $X$ 's consent that $Y \phi$ can make Y's $\phi$-ing all things considered permissible when, by cancelling the protected reason given to $\mathrm{Y}$ by $\mathrm{X}$ 's right, $\mathrm{X}$ makes it the case that $\mathrm{Y}$ now has an undefeated reason for which he can

\footnotetext{
37 Dempsey, "Victimless Conduct," pp. 22-23; John Gardner, "Justifications and Reasons," in his Offences and Defences (Oxford: Oxford University Press, 2007): 91-120. The view of all things considered permissibility that follows in the text can be replaced with any other view that ties all things considered permissibility to an agent's reasons for action without impacting upon my account of the relationship between consent and all things considered permissibility.

${ }^{38}$ I assume here for the sake of simplicity that an action is all things considered permissible if it is justified, and justified if it is all things considered permissible.

39 Dempsey, "Victimless Conduct," p. 17; Thomson, The Realm of Rights, p. 349.
} 
$\phi .{ }^{40}$ To further clarify this idea, return to the example of Surgeons' Consent. In this case, while Steve's and Sally's mutual consent cancels one of the protected reasons they each have (namely, the reason grounded in the normal directed duty they owe one another not to have sex with the other), their consent does not cancel the protected reason they have to save Zack's life. Given the weight of this latter reasonthe weight of the duty of care they owe to Zack-I assume that, even though they have one another's sexual consent, they do not have an undefeated reason to have sex with one another. (Their immediate sexual gratification is much less significant than Zack's life in the circumstances.) If this is true, then, while they will not wrong one another by having sex (a fact which, as I noted earlier, is a significant moral fact about their relationship), their action is not all things considered permissible. ${ }^{41}$ If, by contrast, Steve and Sally were off-duty and at home, with other surgeons tending to Zack, then their mutual consent would (at least normally) suffice to avail them both of an undefeated reason in favour of having sex, viz., their sexual desire. In such circumstances, their having sex will be all things considered permissible.

Understanding consent as a cancelling permission enables us to avoid the overand under-inclusiveness of Dempsey's account. ${ }^{42}$ That is because, on the proposed view, X's consent is only called for when she has a claim-right against Y not to $\phi$, and when $\mathrm{X}$ has a power of consent over this claim-right. Like Dempsey's account, however, the proposed account offers a clear view of how X's consent affects Y's reasons for action, and, therefore, of how it should impact upon Y's practical deliberations, and the all things considered permissibility of Y's actions. Where $\mathrm{X}$ gives $\mathrm{Y}$ consent to $\phi$, she cancels the normal protected reason $\mathrm{Y}$ has not to $\phi$. She thereby alters the reasons that bear on the justification of Y's $\phi$-ing, enabling her to appeal to previously excluded and pre-empted reasons.

\section{Conclusion}

In conclusion, let me briefly recap on the central claims that I have made in this article. In Sect. 2, I outlined a view of consent's normative effect (Permissive Consent), according to which $\mathrm{X}$ 's consent that $\mathrm{Y} \phi$ cancels a directed duty $\mathrm{Y}$ owes to $\mathrm{X}$ not to $\phi$, and thereby other things being equal grants $\mathrm{Y}$ a directed permission to $\phi$. This accounts for the significance that consent has within our interpersonal moral relationships, since X's valid consent will (usually) prevent Y from wronging her. I

\footnotetext{
${ }^{40}$ Cf. John Gardner, "Justification under Authority," Canadian Journal of Law and Jurisprudence 23 (2010): 71-98.

41 Of course, it will also wrong Zack, but that is not the central point I am making here. (In some cases, it may be all things considered permissible to wrong someone).

${ }^{42}$ In her paper, Dempsey does consider a version of the cancellation view ("Victimless Conduct," p. 19). She rejects this view because she mistakenly takes it to imply that X's consent will cancel some of Y's first-order reasons not to $\phi$, for example, reasons grounded in X's well-being. Dempsey is right to reject this version of the view. But, as I explain in the text, consent does not cancel these first-order reasons, but rather, cancels the protected reason given to the consentee by her directed duty to the consenter. When $\mathrm{X}$ 's consent is valid, this prevents $\mathrm{Y}$ from wronging $\mathrm{X}$ (at least, by violating this particular duty), but it does not cancel the ordinary reasons given to $\mathrm{Y}$ by $\mathrm{X}$ 's interests, and these reasons still bear on the justification, and all things considered permissibility, of Y's action.
} 
then argued in Sect. 3 that X's consent affects Y's reasons for action, and so affects the all things considered permissibility of Y's action, by functioning as a cancelling permission. This means that X's consent that Y $\phi$ affects the reasons that bear on the justification Y's $\phi$-ing. Specifically, X's consent enables Y to take into consideration reasons that were previously excluded and pre-empted by X's right. The account leaves many (indeed, most) questions about the ethics of consent unanswered. However, the proposed account provides a framework within which to think about these questions, while accounting for the role that consent plays along two dimensions of our moral thought: concerning, on the one hand, our interpersonal moral relationships, and, on the other hand, the justifiability of our actions.

Acknowledgements I would like to thank Angie Pepper, Daniel Viehoff, and audience members at McMaster University, for helpful comments and feedback on earlier drafts of this article.

Open Access This article is distributed under the terms of the Creative Commons Attribution 4.0 International License (http://creativecommons.org/licenses/by/4.0/), which permits unrestricted use, distribution, and reproduction in any medium, provided you give appropriate credit to the original author(s) and the source, provide a link to the Creative Commons license, and indicate if changes were made. 